Article

\title{
Optimizing the Synthetic Route of Chromone-2-carboxylic Acids: A Step forward to Speed-up the Discovery of Chromone-based Multitarget-directed Ligands
}

\author{
Fernando Cagide * Catarina Oliveira, Joana Reis ${ }^{\dagger}$ and Fernanda Borges *(D) \\ CIQUP/Department of Chemistry and Biochemistry, Faculty of Sciences, University of Porto, Rua do Campo \\ Alegre, 4169-007 Porto, Portugal; catarina.oliveira.fc@gmail.com (C.O.); jocostareis@gmail.com (J.R.) \\ * Correspondence: fernando.fagin@fc.up.pt (F.C.); fborges@fc.up.pt (F.B.) \\ † Present address: Department of Biology and Biotechnology, University of Pavia, Via Ferrata 1, \\ 27100 Pavia, Italy.
}

Academic Editors: Ionel Mangalagiu and John Spencer

Received: 13 September 2019; Accepted: 19 November 2019; Published: 20 November 2019

check for updates

\begin{abstract}
Bromochromone-2-carboxylic acid (3) was synthesized by a microwave-assisted process. The optimization of the reaction was performed varying parameters, such as type of base/number of reagent equivalents, solvent, temperature and reaction time. The yield of the reaction was improved to $87 \%$. The new synthetic route is versatile as several chromone-2-carboxylic acids (compounds 4B-10B) were obtained with good yields (54-93\%). Only in the case of the nitro substituent (compound 11B), an ester was obtained instead of the desired carboxylic acid. Following this synthetic route chromone carboxylic acids can be attained with a high degree of purity, without the need of the tedious and expensive purification processes through column chromatography. The reaction is safe, cost-effective, fast and robust, and can be used in the development of concise and diversity-oriented libraries based on chromone scaffold. The overall study can be looked as a step forward to speed-up the discovery of chromone-based multitarget-directed ligands.
\end{abstract}

Keywords: chromone-2-carboxylic acids; microwave-assisted reaction; multitarget ligands

\section{Introduction}

Chromones are oxygen-containing heterocyclic compounds with a benzoannelated $\gamma$-pyrone ring widely distributed in nature and present in notable amounts in several species $[1,2]$. They are well-known by their diversity of pharmacological properties, such as antiallergic, anti-inflammatory, antidiabetic, antitumor, and antimicrobial [2].

Chromone (4H-chromen-4-one; $4 H$-1-benzopyran-4-one) is a privileged structure used in drug discovery programs, being the scaffold recognized as a pharmacophore of a great number of bioactive molecules [1-3]. As neurodegenerative diseases, such as Alzheimer's and Parkinson's disease, are characterized as multifactorial pathologies, the development of multitarget-directed ligands is a hot drug discovery issue [4]. In this context, following a multitarget strategy, our research group have developed chromone-based multitarget ligands as bifunctional acetylcholinesterase (AChE) and monoamine oxidase (MAO) inhibitors (Figure 1) [5]. 


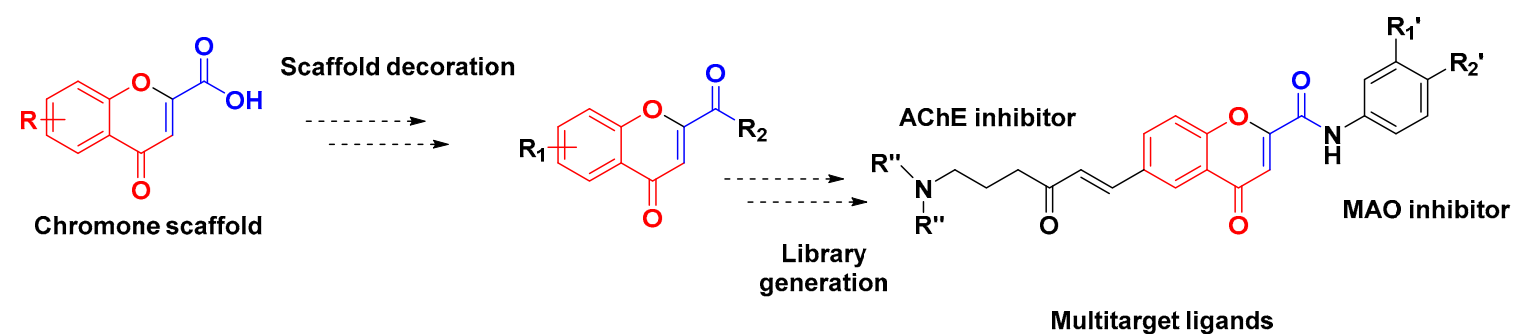

Figure 1. Drug design strategy followed to obtain multitarget ligands based on chromone scaffold.

Within this framework the process development and chemical route scouting for the library generation is of utmost significance. Synthetic routes must be optimized in terms of time, amount of by-products, environmental impact, yield, number of purification steps, among other parameters. In addition, the use of green and sustainable chemistry is also an important issue.

Microwave technology has been used in chemistry since the late 1970s, but it has only been implemented in organic synthesis since the mid-1980s. However, in the past few years, heating chemical reactions by microwave energy has been progressively a more popular subject [6].

The availability of safe, single-mode dedicated MW apparatus has allowed the incorporation of this technology into accelerating hit-to-lead, and lead optimization programs [7-9]. Their use dramatically reduces processing times, increase product yields, and enhance the purity of the product, when compared to the conventional experiments [3].

The functionalization of the chromone scaffold originates remarkable derivatives, namely those possessing a reactive carbonyl group (e.g., carboxylic acid), which are versatile synthons owing to its ability to participate in an extensive spectrum of chemical reactions $[1,3,10]$.

In this work, our main goal was to develop an effective and fast synthetic route to obtain 4-oxo- $4 \mathrm{H}$-chromene-2-carboxylic acid and its derivatives, which are often used in medicinal chemistry to develop small libraries for structure-activity studies (Figure 2). Till now few MW reactions for the novo synthesis of this type of building blocks has been described [11-13].

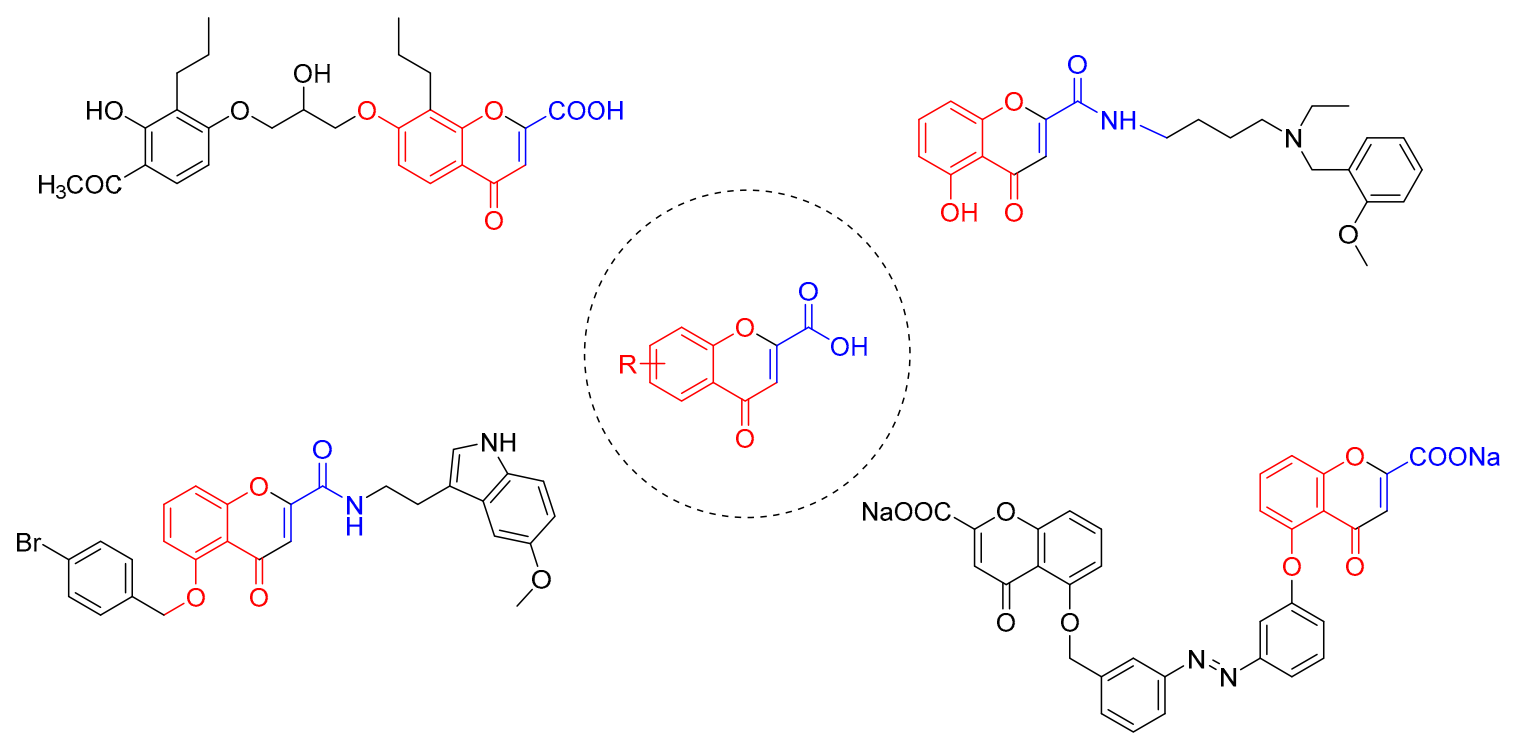

Figure 2. Chromones obtained from 4-oxo-4H-chromene-2-carboxylic acid with relevant biological activity $[1,2]$.

In this context, we started the MW studies with the commercial compound 5'-bromo-2'-hydroxyacetophenone to obtain 6-bromochromone-2-carboxylic acid (3, Scheme 1). Although this chromone is commercially available it is very costly for drug discovery 
programs. After reaction optimization, the study was extended to the synthesis of other 4-oxo-4H-chromene-2-carboxylic acid derivatives in order to obtain the suitable synthons to speed-up the progress on the discovery of chromone-based multitarget-directed ligands.<smiles>CCCCCCCCC(=O)c1cc(Br)ccc1O</smiles>

1

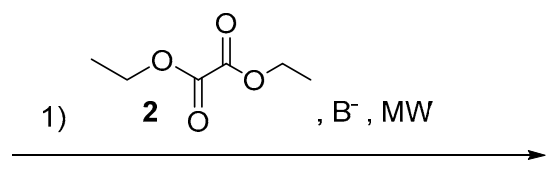

2) $\mathrm{HCl}, \mathrm{MW}$

Scheme 1. General synthetic strategy followed to obtain compound 3.

\section{Results and Discussion}

The synthesis of 6-bromochromone-2-carboxylic acid (3) was initially chosen for the optimization study. As the chromone is commercially available it was used as standard allowing a rapid confirmation of its formation along the reaction by thin-layer chromatography (TLC).

The synthesis of 6-bromochromone-2-carboxylic acid (3) was carried out using $5^{\prime}$-bromo-2'-hydroxyacetophenone (1) as starting material and reaction conditions similar to the classic reaction described in the literature [14].

Herein we describe a method to obtain 6-bromochromone-2-carboxylic acid (3) by a MW-assisted synthesis (Scheme 1) comprising two steps: (1) addition of ethyl oxalate (compound 2) and a base; (2) addition of chloridric acid $(\mathrm{HCl})$ and the studies performed for its optimization, which include diverse parameters-type of base/number of reagent equivalents, solvent, temperature and reaction time.

The study was started with the conditions described in Table 1, Entry 1: sodium ethoxide (EtONa, base, 1 equiv.) in ethanol at $120^{\circ} \mathrm{C}$ and $3 \mathrm{~mL}$ of $\mathrm{HCl}, 1 \mathrm{M}$ for the hydrolysis step. The associated times of the steps (1) and (2) (Time 1 and 2, respectively) were defined as $10 \mathrm{~min}$. With these conditions a low yield (14\%) was obtained (Table 1, Entry 1). When the base was replaced by sodium methoxide (NaOMe) in methanol (Table 1, Entry 2) similar results were obtained. To note that these strong bases are commercially available in alcoholic solutions, and used as such. Based on the data, and our experience on the synthesis of chromones, $\mathrm{NaOMe}$ was the base chosen for the following studies as it is slightly cheaper, more stable and fewer side products were observed by TLC.

The increase of the equivalents number of the base $(\mathrm{NaOMe})$ and of the ethyl oxalate lead to an improvement of the yield of compound 3 (Table 1, Entries 3-6), being the best reactional conditions attained with two equivalents of $\mathrm{NaOMe}$ and three of ethyl oxalate, with a yield of $21 \%$ (Table 1, Entry 6 ). After that, the effect of the acid concentration used in the step 2) was studied (Table 1, Entries 7-8). Although a change of $1 \mathrm{M}$ to $6 \mathrm{M}$ was performed, the yield up only to $30 \%$ (Table 1, Entry 8).

Additional modifications in the temperature and time of the reaction were performed. The increase of the temperature of the first reaction step to $140{ }^{\circ} \mathrm{C}$ resulted in a decrease of the yield to $19 \%$ (Table 1 , Entry 9). However, keeping the temperature at $120^{\circ} \mathrm{C}$ and increasing the reaction time of the step (1) to $20 \mathrm{~min}$, a small increment of the yield to $34 \%$ was observed (Table 1, Entry 10). Nevertheless, longer times of reaction (30 min) did not produce any performance upsurge (Table 1, Entry 11).

To improve the acetophenone solubilization the solvent of the reaction was also changed to a less polar (Table 1, Entries 12,13). The most significant results were obtained when dioxane was used with an increase in yield going from $34 \%$ to $68 \%$ (Table 1, Entry 13). 
Table 1. Microwave-assisted optimization conditions for the synthesis of compound 3.

\begin{tabular}{|c|c|c|c|c|c|c|c|c|}
\hline Entry & $\begin{array}{c}\text { Base } \\
\text { (Equiv) }\end{array}$ & $\begin{array}{c}2 \\
\text { (Equiv) }\end{array}$ & Solvent & $\begin{array}{c}\mathrm{T} \\
\left({ }^{\circ} \mathrm{C}\right)\end{array}$ & $\underset{(\min )}{\operatorname{Time} 1}$ * & $\begin{array}{c}\text { Acid } \\
(\mathrm{V}=3 \mathrm{~mL})\end{array}$ & $\begin{array}{c}\text { Time } 2 * \\
\text { (min) }\end{array}$ & $\begin{array}{c}\text { Yield } \\
(\%)\end{array}$ \\
\hline 1 & EtONa (1) & 1 & $\mathrm{EtOH}$ & 120 & 10 & $\mathrm{HCl}(1 \mathrm{M})$ & 10 & 14 \\
\hline 2 & MeONa (1) & 1 & $\mathrm{MeOH}$ & 120 & 10 & $\mathrm{HCl}(1 \mathrm{M})$ & 10 & 15 \\
\hline 3 & $\mathrm{MeONa}(2)$ & 1 & $\mathrm{MeOH}$ & 120 & 10 & $\mathrm{HCl}(1 \mathrm{M})$ & 10 & 19 \\
\hline 4 & $\mathrm{MeONa}(3)$ & 1 & $\mathrm{MeOH}$ & 120 & 10 & $\mathrm{HCl}(1 \mathrm{M})$ & 10 & 17 \\
\hline 5 & $\mathrm{MeONa}(2)$ & 2 & $\mathrm{MeOH}$ & 120 & 10 & $\mathrm{HCl}(1 \mathrm{M})$ & 10 & 19 \\
\hline 6 & $\mathrm{MeONa}(2)$ & 3 & $\mathrm{MeOH}$ & 120 & 10 & $\mathrm{HCl}(1 \mathrm{M})$ & 10 & 21 \\
\hline 7 & $\mathrm{MeONa}(2)$ & 3 & $\mathrm{MeOH}$ & 120 & 10 & $\mathrm{HCl}(3 \mathrm{M})$ & 10 & 23 \\
\hline 8 & $\mathrm{MeONa}(2)$ & 3 & $\mathrm{MeOH}$ & 120 & 10 & $\mathrm{HCl}(6 \mathrm{M})$ & 10 & 30 \\
\hline 9 & $\mathrm{MeONa}(2)$ & 3 & $\mathrm{MeOH}$ & 140 & 10 & $\mathrm{HCl}(6 \mathrm{M})$ & 10 & 19 \\
\hline 10 & $\mathrm{MeONa}(2)$ & 3 & $\mathrm{MeOH}$ & 120 & 20 & $\mathrm{HCl}(6 \mathrm{M})$ & 10 & 34 \\
\hline 11 & $\mathrm{MeONa}(2)$ & 3 & $\mathrm{MeOH}$ & 120 & 30 & $\mathrm{HCl}(6 \mathrm{M})$ & 10 & 34 \\
\hline 12 & $\mathrm{MeONa}(2)$ & 3 & ${ }^{\mathrm{i}} \mathrm{PrOH}$ & 120 & 20 & $\mathrm{HCl}(6 \mathrm{M})$ & 10 & 51 \\
\hline 13 & $\mathrm{MeONa}(2)$ & 3 & Dioxane & 120 & 20 & $\mathrm{HCl}(6 \mathrm{M})$ & 10 & 68 \\
\hline 14 & $\mathrm{MeONa}(2)$ & 3 & Dioxane & 120 & 20 & $\mathrm{HCl}(6 \mathrm{M})$ & 30 & 81 \\
\hline 15 & $\mathrm{MeONa}(2)$ & 3 & Dioxane & 120 & 20 & $\mathrm{HCl}(6 \mathrm{M})$ & 40 & 87 \\
\hline 16 & MeONa (2) & 3 & Dioxane & 120 & 20 & $\mathrm{HCl}(1 \mathrm{M})$ & 50 & 85 \\
\hline
\end{tabular}

The final optimization step was related with the increment of the hydrolysis time of the ester (step 2, Table 1, Entries 14,15): 40 min allowed to obtain compound 3 with a yield of $87 \%$ (Table 1, Entry 15). Likewise, longer times of reaction $(50 \mathrm{~min}$ ) did not produce an additional increase of the performance of the reaction (Table 1, Entry 16).

After the reaction optimization its versatility was verified using dissimilar 2'-hydroxyacetophenone derivatives (A) to obtain chromone-2-carboxylic acid derivatives (B) having different type of substituents (Table 2). The selected substituents are often used in medicinal chemistry programs $[15,16]$.

When the 2 -hydroxyacetophenone without substituents in the aromatic ring (compound 4A) was used, a decrease in yield (compound $\mathbf{4 B}, 54 \%$, Table 2) was observed in comparison with the obtained 6-bromochromone-2-carboxylic acid (compound 3, 87\%, Table 1, Entry 15). The replacement of bromine by a chlorine in the aromatic ring (compound $5 \mathrm{~A}$ ) allowed to obtain the desired chromone with a slight lower yield (compound $5 \mathbf{B}, 71 \%$, Table 2). A similar behavior was observed when the 2 '-hydroxyacetophenone substituent was a methyl group (compound 6B, 64\%, Table 2). When the acetophenone is substituted with one methoxyl group (compounds $\mathbf{7 A}, \mathbf{8 A}$ and $\mathbf{9 A}$ ) a similar reaction performance to compound 3, with yields between $81-93 \%$ (compounds $\mathbf{7 B}, \mathbf{8 B}$ and $\mathbf{9 B}$, Table 2) was obtained. However, when the $2^{\prime}$-hydroxyacetophenone has two methoxy substituents in positions 7 and 8 (compound 10A) a reduction of the reaction yield to $62 \%$ was observed (compound 10B, Table 2).

As all the purification steps were based only on the washing process, without further purification by column chromatography, a loss of mass along the process was, in general, observed.

Finally, when the aromatic ring possesses a nitro group in position 6 (compound 11A), instead of the desired chromone carboxylic acid, the corresponding methyl ester was obtained. This shortcoming can be related to the presence of a highly deactivating substituent that can preclude ester hydrolysis by stabilizing the reaction intermediate or by bring about a compound with low solubility in the reaction media. 
Table 2. Synthesis of chromone-2-carboxylic acids by microwave-assisted reaction.

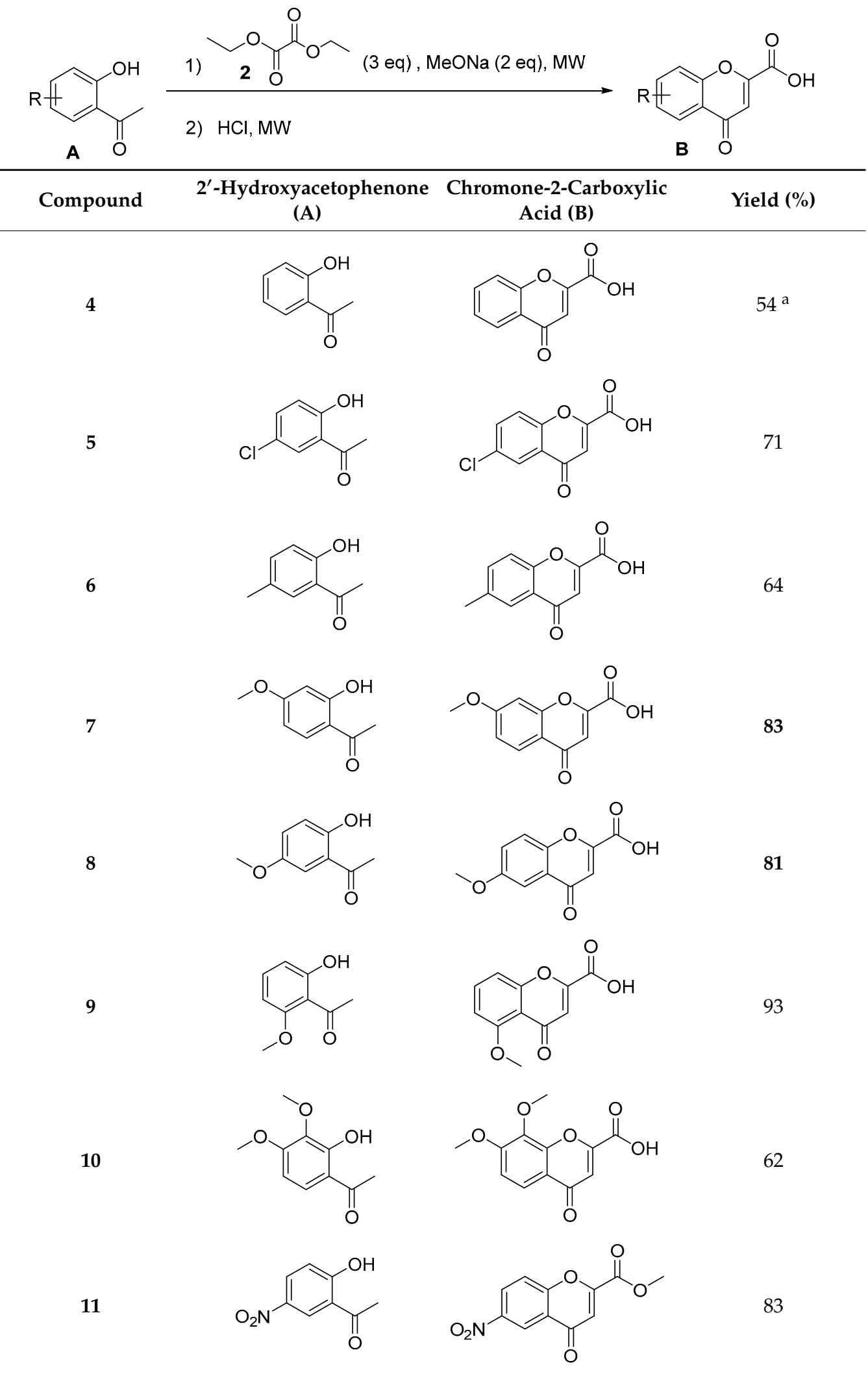

a. The yield of the compound has been previously described, for similar reaction conditions and with a domestic MW apparatus, as 93\% [17]. 


\section{Material and Methods}

\subsection{Apparatus}

Microwave-assisted synthesis was performed in a Biotage ${ }^{\circledR}$ Initiator Microwave Synthesizer (Biotage, Uppsala, Sweden). ${ }^{1} \mathrm{H}$ - and ${ }^{13} \mathrm{C}-\mathrm{NMR}$ spectra were recorded on an AMX 400 NMR spectrometer (Bruker, Billerica, MA, USA). Spectra were recorded at room temperature in $5 \mathrm{~mm}$ outside diameter (o.d.) tubes. Tetramethylsilane (TMS) was used as internal standard, chemical shifts are expressed in ppm $(\delta)$ and $J$ in $\mathrm{Hz}$. For the DEPT sequence, the width of the $90^{\circ}$ pulse for ${ }^{13} \mathrm{C}$ was $4 \mu \mathrm{s}$, and that of the $90^{\circ}$ pulse for ${ }^{1} \mathrm{H}$ was $9.5 \mu \mathrm{s}$; the delay $2 \mathrm{JC}, \mathrm{H}-1$ was set to $3.5 \mathrm{~ms}$ (underlined values). The melting point were carried out on a Stuart Scientific Melting Point SMP1 apparatus (Stuart Scientific, Staffordshire, UK).

\subsection{Reagents and General Conditions}

All reagents were purchased from Sigma-Aldrich Química S.A. (Lisbon, Portugal) and TCI Chemicals Europe (Paris, French). All solvents were pro analysis grade from Merck (Darmstadt, Germany), Carlo Erba Reagents (Val de Reuil, France) and Scharlab (Barcelona, Spain).

Thin layer chromatography (TLC) was performed on precoated silica gel 60 F254 acquired from Merck with layer thickness of $0.2 \mathrm{~mm}$. Reaction control was monitored using ethyl acetate and/or ethyl acetate:methanol (9:1) and spots were visualized under UV detection at 254 and $366 \mathrm{~nm}$.

\subsection{Synthesis of 4-Oxo-4H-chromene-2-carboxylic acids 3-11}

General Procedure

The appropriate hydroxyacetophenone $(\mathbf{1}$ or $\mathbf{A}, 1.16 \mathrm{mmol})$ was dissolved in dioxane $(2 \mathrm{~mL})$ in a MW vial. Then diethyl oxalate $(3.49 \mathrm{mmol}, 474 \mu \mathrm{L})$ and a solution of MeONa in $\mathrm{MeOH}(2.32 \mathrm{mmol}$, $531 \mu \mathrm{L}, 25 \% \mathrm{w} / \mathrm{w}$ ) were added. The resulting solution was heated to $120^{\circ} \mathrm{C}$ for $20 \mathrm{~min}$. Then, a solution of $\mathrm{HCl}(18 \mathrm{mmol}, 3 \mathrm{~mL}, 6 \mathrm{M})$ was added and the reaction was heated to $120^{\circ} \mathrm{C}$ for $40 \mathrm{~min}$. The reaction was decanted over water $(50 \mathrm{~mL})$ and the solid formed was filtered and washed with water. The solid was then dried, washed with dichloromethane and dried again.

6-Bromo-4-oxo-4H-chromene-2-carboxylic acid (3): $\eta=87 \%,{ }^{1} \mathrm{H}-\mathrm{NMR}\left(\mathrm{DMSO}-\mathrm{d}_{6}\right) \delta: 8.12(1 \mathrm{H}, d$, $J=2.4 \mathrm{~Hz}, \mathrm{H} 5), 8.03\left(1 \mathrm{H}, d d, J_{1}=9.0 \mathrm{~Hz}, J_{2}=2.5 \mathrm{~Hz}, \mathrm{H} 7\right), 7.74(1 \mathrm{H}, d, J=9.0 \mathrm{~Hz}),, 6.95(1 \mathrm{H}, s, \mathrm{H} 3)$. ${ }^{13} \mathrm{C}-\mathrm{NMR}\left(\mathrm{DMSO}-\mathrm{d}_{6}\right) \delta 176.4(\mathrm{C} 4), 160.9(\mathrm{COOH}), 154.4(\mathrm{C} 2), 153.6(\mathrm{C} 8 \mathrm{a}), 137.7$ (C6), 126.9 (C5), 125.2 (C4a), 121.5 (C3), 118.4 (C6), 113.4 (C8). M.p.: $263-267^{\circ} \mathrm{C}$.

4-Oxo-4H-chromene-2-carboxylic acid (4B): $\eta=54 \%,{ }^{1} \mathrm{H}-\mathrm{NMR}(\mathrm{MeOD}) \delta: 8.17\left(1 \mathrm{H}, d d, J_{1}=8.0 \mathrm{~Hz}\right.$, $\left.J_{2}=1.7 \mathrm{~Hz}, \mathrm{H} 5\right), 7.88\left(1 \mathrm{H}, d d d, J_{1}=8.7 \mathrm{~Hz}, J_{2}=7.1 \mathrm{~Hz}, J_{3}=1.7 \mathrm{~Hz}, \mathrm{H7}\right), 7.72\left(1 \mathrm{H}, d d, J_{1}=8.7, J_{1}\right.$ $=1.1 \mathrm{~Hz}, \mathrm{H} 8), 7.55\left(1 \mathrm{H}, d d d, J_{1}=8.0 \mathrm{~Hz}, J_{2}=7.1 \mathrm{~Hz}, J_{3}=1.1 \mathrm{~Hz}, \mathrm{H} 6\right), 7.08(1 \mathrm{H}, \mathrm{s}, \mathrm{H} 3) .{ }^{13} \mathrm{C}-\mathrm{NMR}$ $\left(\mathrm{MeOD}_{4} \mathrm{~d}_{4}\right)$ 8:179.4 (C4), $161.5(\mathrm{COOH}), 156.2$ (C2), 153.9 (C8a), 135.1 (C7), 125.9 (C5), 124.9 (C6), 123.8 (C4a), 118.6 (C3), 113.3 (C8). M.p.: $>285^{\circ} \mathrm{C}$ dec.

6-Chloro-4-oxo-4H-chromene-2-carboxylic acid (5B): $\eta=71 \%,{ }^{1} \mathrm{H}-\mathrm{NMR}\left(\mathrm{DMSO}-\mathrm{d}_{6}\right) \delta: 8.08(1 \mathrm{H}, d$, $J=2.6 \mathrm{~Hz}, \mathrm{H} 5), 7.83\left(1 \mathrm{H}, d d, J_{1}=9.0, J_{2}=2.6 \mathrm{~Hz}, \mathrm{H} 7\right), 7.71(1 \mathrm{H}, d, J=9.0 \mathrm{~Hz}, \mathrm{H} 8), 7.06(1 \mathrm{H}, s, \mathrm{H} 3)$.

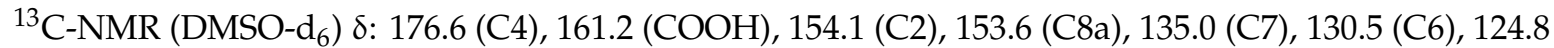
(C5), 123.9 (C2a), 121.4 (C3), 113.3 (C8). M.p.: 280-284 ${ }^{\circ} \mathrm{C}$.

6-Methyl-4-oxo-4H-chromene-2-carboxylic acid (6B): $\eta=64 \%,{ }^{1} \mathrm{H}-\mathrm{NMR}(400 \mathrm{MHz}, \mathrm{MeOD}) \delta: 7.92$ $(1 \mathrm{H}, d, J=2.3 \mathrm{~Hz}, \mathrm{H} 5), 7.68\left(1 \mathrm{H}, d d, J_{1}=8.7, J_{2}=2.3 \mathrm{~Hz}, \mathrm{H} 6\right), 7.58(1 \mathrm{H}, d, J=8.6 \mathrm{~Hz}, \mathrm{H} 8), 7.02(1 \mathrm{H}, s$, H3), $2.48\left(3 \mathrm{H}, s, \mathrm{CH}_{3}\right) .{ }^{13} \mathrm{C}-\mathrm{NMR}\left(\mathrm{MeOD}_{4} \mathrm{~d}_{4}\right) \delta: 180.8(\mathrm{C} 4), 163.0(\mathrm{COOH}), 156.0(\mathrm{C} 2), 155.1(\mathrm{C} 8 \mathrm{a}), 137.8$ (C7), 137.7 (C6), 125.5 (C5), 125.0 (C4a), 119.8 (C3), $114.6(\mathrm{C} 8), 21.0\left(\mathrm{CH}_{3}\right)$. M.p.: >279 ${ }^{\circ} \mathrm{C}$ dec.

7-Methoxy-4-oxo-4H-chromene-2-carboxylic acid (7B): $\eta=83 \%,{ }^{1} \mathrm{H}-\mathrm{NMR}\left(\mathrm{DMSO}-\mathrm{d}_{6}\right) \delta: 7.95(1 \mathrm{H}, d$, $J=9.2 \mathrm{~Hz}, \mathrm{H} 5), 7.22(1 \mathrm{H}, d, J=2.4 \mathrm{~Hz}, \mathrm{H} 8), 7.12\left(1 \mathrm{H}, d d, J_{1}=9.2 \mathrm{~Hz}, J_{2}=2.4 \mathrm{~Hz}, \mathrm{H} 6\right), 6.86(1 \mathrm{H}, s, \mathrm{H} 3)$, $3.94\left(3 \mathrm{H}, \mathrm{s}, \mathrm{OCH}_{3}\right) .{ }^{13} \mathrm{C}-\mathrm{NMR}\left(\mathrm{DMSO}_{6}\right)$ 8: $177.2(\mathrm{C} 4), 165.1(\mathrm{C} 7), 161.9(\mathrm{COOH}), 158.0(\mathrm{C} 2), 153.6$ (C8a), 126.9 (C5), 118.2 (C4a), 116.1 (C3), $114.2(\mathrm{C} 6), 101.5(\mathrm{C} 8), 56.8\left(\mathrm{OCH}_{3}\right)$. M.p.: $283-287^{\circ} \mathrm{C}$. 
6-Methoxy-4-oxo-4H-chromene-2-carboxylic acid (8B): $\eta=81 \%,{ }^{1} \mathrm{H}-\mathrm{NMR}\left(\mathrm{DMSO}_{6}\right) \delta: 7.71(1 \mathrm{H}, d, J$ $=9.2 \mathrm{~Hz}, \mathrm{H} 8), 7.47\left(1 \mathrm{H}, d d, J_{1}=9.2 \mathrm{~Hz}, J_{1}=3.2 \mathrm{~Hz}, \mathrm{H} 7\right), 7.42(1 \mathrm{H}, d, J=3.2 \mathrm{~Hz}, \mathrm{H} 5), 6.89(1 \mathrm{H}, s, \mathrm{H} 3)$, $3.88\left(3 \mathrm{H}, s, \mathrm{OCH}_{3}\right) .{ }^{13} \mathrm{C}-\mathrm{NMR}\left(\mathrm{DMSO}_{6}\right)$ 8: $177.3(\mathrm{C} 4), 161.5(\mathrm{COOH}), 157.0(\mathrm{C} 2), 153.0(\mathrm{C} 6), 150.2$ (C8a), 124.5 (C4a), 124.4 (C7), 120.5 (C3), 112.5 (C8), 104.5 (C5), $55.8\left(\mathrm{OCH}_{3}\right)$. M.p.: 293-294 ${ }^{\circ} \mathrm{C}$.

5-Methoxy-4-oxo-4H-chromene-2-carboxylic acid (9B): $\eta=93 \%,{ }^{1} \mathrm{H}-\mathrm{NMR}(\mathrm{MeOD}) \delta: 7.73(1 \mathrm{H}, d d$, $\left.J_{1}=8.5 \mathrm{~Hz}, J_{2}=8.5 \mathrm{~Hz}, 7 \mathrm{H}\right), 7.20\left(1 \mathrm{H}, d d, J=8.5, J_{2}=0.9 \mathrm{~Hz}, \mathrm{H} 8\right), 7.03\left(1 \mathrm{H}, d d, J=8.5, J_{2}=0.9 \mathrm{~Hz}\right.$, H6), $6.91(1 \mathrm{H}, s, \mathrm{H} 3), 3.95\left(3 \mathrm{H}, s, \mathrm{OCH}_{3}\right) .{ }^{13} \mathrm{C}-\mathrm{NMR}\left(\mathrm{MeOD}-\mathrm{d}_{4}\right)$ 8: $179.1(\mathrm{C} 4), 161.4(\mathrm{COOH}), 159.6$ (C2), 158.1 (C5), 151.8 (C8a), 135.4 (C7) 115.0 (C3), 114.2 (C4a), 110.1 (C6), 107.0 (C8), $55.3\left(\mathrm{OCH}_{3}\right)$. M.p.: $>256^{\circ} \mathrm{C}$ dec.

7,8-Dimethoxy-4-oxo-4H-chromene-2-carboxylic acid (10B): $\eta=62 \%,{ }^{1} \mathrm{H}-\mathrm{NMR}\left(\mathrm{DMSO}-\mathrm{d}_{6}\right) \delta: 7.77(1 \mathrm{H}$, $d, J=9.0 \mathrm{~Hz}, \mathrm{H} 5), 7.31(1 \mathrm{H}, d, J=9.0 \mathrm{~Hz}, \mathrm{H} 6), 6.82(1 \mathrm{H}, \mathrm{s}, \mathrm{H} 3), 3.95\left(3 \mathrm{H}, \mathrm{s}, \mathrm{OCH}_{3}\right), 3.91\left(3 \mathrm{H}, \mathrm{s}, \mathrm{OCH}_{3}\right)$. ${ }^{13}$ C-NMR (DMSO-d 6 ) $8: 176.9(\mathrm{C} 4), 161.4(\mathrm{COOH}), 156.8(\mathrm{C} 2), 152.9(\mathrm{C} 7), 149.7$ (C8a), 136.5 (C8), 120.1 (C3), $118.3(\mathrm{C} 4 \mathrm{a}), 112.9$ (C5), $111.4(\mathrm{C} 7), 60.9\left(\mathrm{OCH}_{3}\right), 56.5\left(\mathrm{OCH}_{3}\right)$. M.p.: $>287^{\circ} \mathrm{C}$ dec.

Methyl 6-nitro-4-oxo-4H-chromene-2-carboxylate (11B): $\eta=83 \%,{ }^{1} \mathrm{H}-\mathrm{NMR}\left(\mathrm{DMSO}-\mathrm{d}_{6}\right) \delta: 8.72(1 \mathrm{H}, d$, $J=2.8 \mathrm{~Hz}, \mathrm{H6}), 8.61\left(1 \mathrm{H}, d d, J_{1}=9.2, J_{2}=2.8 \mathrm{~Hz}, \mathrm{H7}\right), 8.00(1 \mathrm{H}, d, J=9.2 \mathrm{~Hz}, \mathrm{H} 7), 7.03(1 \mathrm{H}, \mathrm{s}, \mathrm{H} 3), 3.57$ $\left(3 \mathrm{H}, \mathrm{s}, \mathrm{OCH}_{3}\right) .{ }^{13} \mathrm{C}-\mathrm{NMR}\left(\mathrm{DMSO}_{6}\right)$ ) $: 176.9(\mathrm{C} 4), 160.9\left(\mathrm{COOCH}_{3}\right), 158.5(\mathrm{C} 2), 154.0(\mathrm{C} 8 \mathrm{a}), 144.7$ (C6), 129.2 (C7), 123.7 (C4a), 121.2 (C5), 120.9 (C3), 113.7 (C8), $66.3\left(\mathrm{OCH}_{3}\right)$. M.p.: 274-279 ${ }^{\circ} \mathrm{C}$.

Details of apparatus and NMR spectra of the synthesized compounds are available in Supplementary Materials.

\section{Conclusions}

The synthesis of 6-bromochromone-2-carboxylic acid (3) using 5'-bromo-2'-hydroxy-acetophenone (1) as starting material and ethyl oxalate (2) was successfully accomplished using a MW-assisted process. For the optimization process a number of parameters were adjusted, such as type of base/number of reagent equivalents, solvent, temperature and reaction time. The yield of the reaction was improved to $87 \%$.

The new synthetic route is versatile as several chromone-2-carboxylic acids (compounds 4B-10B) were obtained with good yields (54-93\%). Only in the case of the nitro substituent (compound 11B), an ester was obtained instead of the desired carboxylic acid.

Following this synthetic route, a variety of chromone carboxylic acids can be attained with a high degree of purity, without the need of the tedious and expensive purification processes through column chromatography. This is a great advantage for the scale-up of the process.

The reaction is safe, cost-effective, fast, robust, and can be used in the development of concise and diversity-oriented libraries based on chromone scaffold. The overall study can be looked as a step forward to speed-up the progress of chromone-based multitarget-directed ligands.

Supplementary Materials: The following are available online, Details apparatus and NMR spectra of the synthesized compounds can be found in the Supporting Information.

Author Contributions: F.C., C.O., J.R., F.B.: Designed the project, synthesized the compounds, analysed the data and wrote the paper. All authors revised the manuscript and agreed with submission.

Funding: This work was funded by FEDER funds through the Operational Programme Competitiveness Factors-COMPETE and national funds by FCT-Foundation for Science and Technology under research grants UID/QUI/00081/2019 and FEDER/COMPETE POCI-01-0145-FEDER-028397. This article is based upon work from COST Action CA15135.

Conflicts of Interest: The authors declare no conflict of interest.

\section{Abbreviations}

AChE Acetylcholinesterase

MAO Monoamine oxidase

MW Microwave

TLC Thin-layer chromatography 


\section{References}

1. Gaspar, A.; Matos, M.J.; Garrido, J.; Uriarte, E.; Borges, F. Chromone: A Valid Scaffold in Medicinal Chemistry. Chem. Rev. 2014, 114, 4960-4992. [CrossRef] [PubMed]

2. Reis, J.; Gaspar, A.; Milhazes, N.; Borges, F. Chromone as a Privileged Scaffold in Drug Discovery: Recent Advances. J. Med. Chem. 2017, 60, 7941-7957. [CrossRef] [PubMed]

3. Cagide, F.; Reis, J.; Gaspar, A.; Borges, F. Accelerating lead optimization of chromone carboxamide scaffold throughout microwave-assisted organic synthesis. Tetrahedron Lett. 2011, 52, 6446-6449. [CrossRef]

4. Oliveira, C.; Cagide, F.; Teixeira, J.; Amorim, R.; Sequeira, L.; Mesiti, F.; Silva, T.; Garrido, J.; Remião, F.; Vilar, S.; et al. Hydroxybenzoic Acid Derivatives as Dual-Target Ligands: Mitochondriotropic Antioxidants and Cholinesterase Inhibitors. Front. Chem. 2018, 6, 126. [CrossRef] [PubMed]

5. Reis, J.; Cagide, F.; Valencia, M.E.; Teixeira, J.; Bagetta, D.; Perez, C.; Uriarte, E.; Oliveira, P.J.; Ortuso, F.; Alcaro, S.; et al. Multi-target-directed ligands for Alzheimer's disease: Discovery of chromone-based monoamine oxidase/cholinesterase inhibitors. Eur. J. Med. Chem. 2018, 158, 781-800. [CrossRef] [PubMed]

6. Kappe, C.O.; Stadler, A. Microwaves in Organic and Medicinal Chemistry. Microwaves in Organic Synthesis, 2nd ed.; Loupy, A., Ed.; Wiley-VCH: Weinheim, Germany, 2006; pp. 134-218.

7. Wathey, B.; Tierney, J.; Lidström, P.; Westman, J. The impact of microwave-assisted organic chemistry on drug discovery. Drug Discov. Today 2002, 7, 373-380. [CrossRef]

8. Shipe, W.D.; Wolkenberg, S.E.; Lindsley, C.W. Accelerating lead development by microwave-enhanced medicinal chemistry. Drug Discov. Today Technol. 2005, 2, 155-161. [CrossRef] [PubMed]

9. Stadler, A.; Kremsner, J.M. Microwave-assisted processing techniques in medicinal chemistry. Microwaves in Drug Discovery and Development: Recent Advances, 1st ed.; Spencer, J., Bagley, M.C., Eds.; Future Medicine Ltd.: London, U.K, 2014; pp. 6-19.

10. Ellis, G.P. Chromenes, Chromanones, and Chromones. the Chemistry of Heterocyclic Compounds, 1st ed.; Ellis John, G.P., Ed.; Wiley \& Sons: New York, NY, USA, 1977.

11. Friden-Saxin, M.; Pemberton, N.; Andersson, K.; Dyrager, C.; Friberg, A.; Grotli, M.; Luthman, K. Synthesis of 2-Alkyl-Substituted Chromone Derivatives Using Microwave Irradiation. J. Org. Chem. 2009, 74, 2755-2759. [CrossRef] [PubMed]

12. Goel, S.; Ritu, R.; Makrandi, J.K. Microwave assisted synthesis of 1-(2-hydroxyphenyl)-5-phenylpent-4-ene-1, 3-diones and their conversion to 2-styrylchromones. Indian J. Chem. Sect. B 2006, 45, 1278-1281. [CrossRef]

13. Balakrishna, C.; Kandula, V.; Gudipati, R.; Yennam, S.; Devi, P.U.; Behera, M. An Efficient Microwave-Assisted Propylphosphonic Anhydride (T3P)-Mediated One Chromone Synthesis via Enaminones. Synlett 2018, 29, 1087-1091.

14. Zagorevskii, V.A.; Glozman, S.M.; Klyuev, S.M. Researches on pyranes, their analogs, and related compounds. Chem. Heterocycl. Compd. 1967, 3, 592-595. [CrossRef]

15. Patani, G.A.; LaVoie, E.J. Bioisosterism: A rational approach in drug design. Chem. Rev. 1996, 96, 3147-3176. [CrossRef] [PubMed]

16. Lemke, T.L.; Williams, D.A.; Roche, V.F.; Zito, S.W. Foye's Principles of Medicinal Chemistry, 7th ed.; Lippincott Williams \& Wilkins: Baltimore, MD, USA, 2013.

17. Bratulescu, G. Excellentes voies de synthese des derives des 4-oxo-4H-1-benzopyranes avec le concours de micro-ondes. Acta Chim. Slov. 2002, 49, 173-180.

Sample Availability: Samples of the compounds are available from the authors. 